\begin{tabular}{lllllll}
\hline & $R$ & $E$ & $V$ & I & $E$ & $W$
\end{tabular}

\title{
Real-time reverse transcription PCR (qRT-PCR) and its potential use in clinical diagnosis
}

\author{
Stephen A. BUSTIN* and Reinhold MUELLER†
}

*Centre for Academic Surgery, Institute of Cell and Molecular Science, Barts and The London, Queen Mary's School of Medicine and Dentistry, University of London, London EI IBB, U.K., and †Stratagene Inc., IIOII N. Torrey Pines Road, La Jolla, CA 92037, U.S.A.

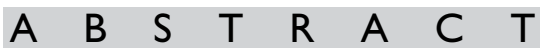

qRT-PCR (real-time reverse transcription-PCR) has become the benchmark for the detection and quantification of RNA targets and is being utilized increasingly in novel clinical diagnostic assays. Quantitative results obtained by this technology are not only more informative than qualitative data, but simplify assay standardization and quality management. qRT-PCR assays are most established for the detection of viral load and therapy monitoring, and the development of SARS (severe acute respiratory syndrome)-associated coronavirus qRT-PCR assays provide a textbook example of the value of this technology for clinical diagnostics. The widespread use of qRT-PCR assays for diagnosis and the detection of disease-specific prognostic markers in leukaemia patients provide further examples of their usefulness. Their value for the detection of diseaseassociated mRNA expressed by circulating tumour cells in patients with solid malignancies is far less apparent, and the clinical significance of results obtained from such tests remains unclear. This is because of conceptual reservations as well as technical limitations that can interfere with the diagnostic specificity of qRT-PCR assays. Therefore, although it is evident that qRT-PCR assay has become a useful and important technology in the clinical diagnostic laboratory, it must be used appropriately and it is essential to be aware of its limitations if it is to fulfil its potential.

\section{INTRODUCTION}

qRT-PCR [real-time RT (reverse transcription)-PCR] [1] has become the standard for the detection and quantification of RNA targets [2] and is firmly established as a mainstream research technology [3]. Its potential for high-throughput, together with regular introduction of enhanced or novel chemistries, more reliable instrumentation and improved protocols, has also seen the development of qRT-PCR-based clinical diagnostic assays [4-6]. Although not necessarily more sensitive than conventional RT-PCR [7], qRT-PCR assays have several significant advantages [8]: (i) they use fluorescent reporter molecules to monitor the production of amplification products during each cycle of the PCR, and the combination of the DNA amplification and detection steps into one homogeneous assay obviates the requirement for post-PCR processing; (ii) their wide dynamic range allows the analysis of samples differing in target abundance by orders of magnitude; (iii) there is little inter-assay variation, which helps generate reliable and reproducible results; and (iv) fluorescence-based qRTPCR realizes the inherent quantitative capacity of PCRbased assays [9], making it a quantitative rather than a qualitative assay. This is important as there is an obvious need in molecular medicine for quantitative data, e.g. for

Key words: cancer, colon, leukaemia, occult disease, pathogen, real-time reverse transcription-PCR (qRT-PCR), virus detection. Abbreviations: APL, acute promyelocytic leukaemia; CEA, carcinoembryonic antigen; $C_{t}$, threshold cycle; CV, coefficient of variance; ds, double stranded; FFPE, formalin-fixed paraffin-embedded; IPCR, immunopolymerase chain reaction; LN, lymph nodes; MRD, minimal residual disease; PIV, parainfluenza virus types; qRT-PCR, real-time RT-PCR; RNase, ribonuclease; RSV, respiratory syncytial virus; RT, reverse transcription; SARS, severe acute respiratory syndrome; SCT, stem cell transplantation; ss, single-stranded; $T_{\mathrm{m}}$, melting temperature.

Correspondence: Professor Stephen A. Bustin (email s.a.bustin@qmul.ac.uk). 


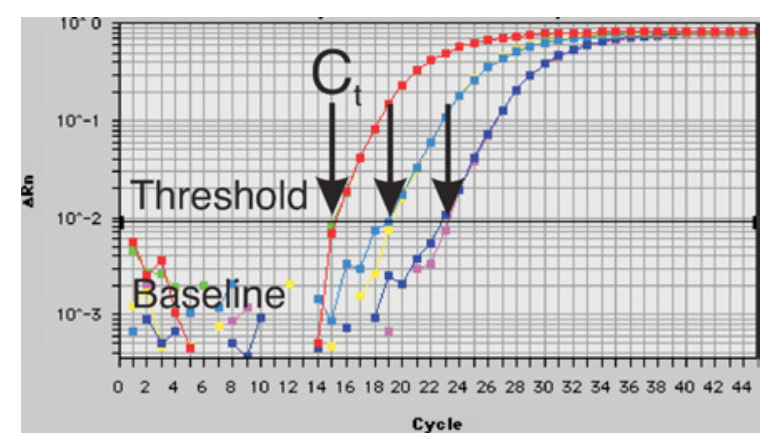

Figure I Characteristics of qRT-PCR amplification curves, which plot fluorescence signal versus cycle number

The curves for three samples, run in duplicate, are shown. $C_{t}$ values are indicated by arrows and represent the cycle fractions where the instrument can first reliably detect fluorescence derived from the amplification reaction. The fluorescence signal during the initial cycles of the $P C R$ is below the instrument's detection threshold and defines the baseline for the amplification plot. An increase in fluorescence above the threshold indicates the detection of accumulated PCR product. The key parameter $C_{t}$ is defined as the fractional cycle number from clinical samples at which the fluorescence passes a fixed threshold chosen either by the instrument or by the operator. A plot of the log of initial target copy number for a set of standards versus $C_{t}$ is a straight line. The amount of target in an unknown sample is quantified by measuring the $C_{\mathrm{t}}$ and using the standard curve to determine starting copy number.

measuring viral load or monitoring of response to therapy in haematological malignancies.

In theory, RT-PCR differs from PCR only by the addition of a preliminary step, the initial conversion of RNA into a DNA template by an RNA-dependent DNA polymerase (reverse transcriptase). In practice, this additional procedure results in a much more fragile and variable assay $[10,11]$. Nevertheless, despite the problems associated with this technique, its promise has resulted in a concerted effort to develop diagnostic assays that make use of the assay's strengths, whilst trying to circumvent its pitfalls [12].

\section{WHAT IS qRT-PCR?}

The principle of qRT-PCR assays is straightforward: following the RT of RNA into cDNA, it requires a suitable detection chemistry to report the presence of PCR products, an instrument to monitor the amplification in realtime and appropriate software for quantitative analysis [13]. qRT-PCRs are characterized by the point in time during cycling when amplification of a PCR product is first detected (Figure 1). The higher the starting copy number of the nucleic acid target, the sooner a significant increase in fluorescence is observed.

Detection chemistries can be either probe- or nonprobe based, also referred to as 'specific' and 'non-specific' respectively. The most widely used non-probe-based chemistry detects the binding of SYBR Green I to ds (double-stranded) DNA [14]. In solution, the unbound dye exhibits little fluorescence; during the PCR assay, increasing amounts of dye bind to the nascent ds DNA. When monitored in real-time, this results in an increase in the fluorescence signal as the polymerization proceeds. The PCR product can be verified by plotting fluorescence as a function of temperature to generate a melting curve of the amplicon [15] (Figure 2). An important advantage of non-probe-based chemistries is that in most

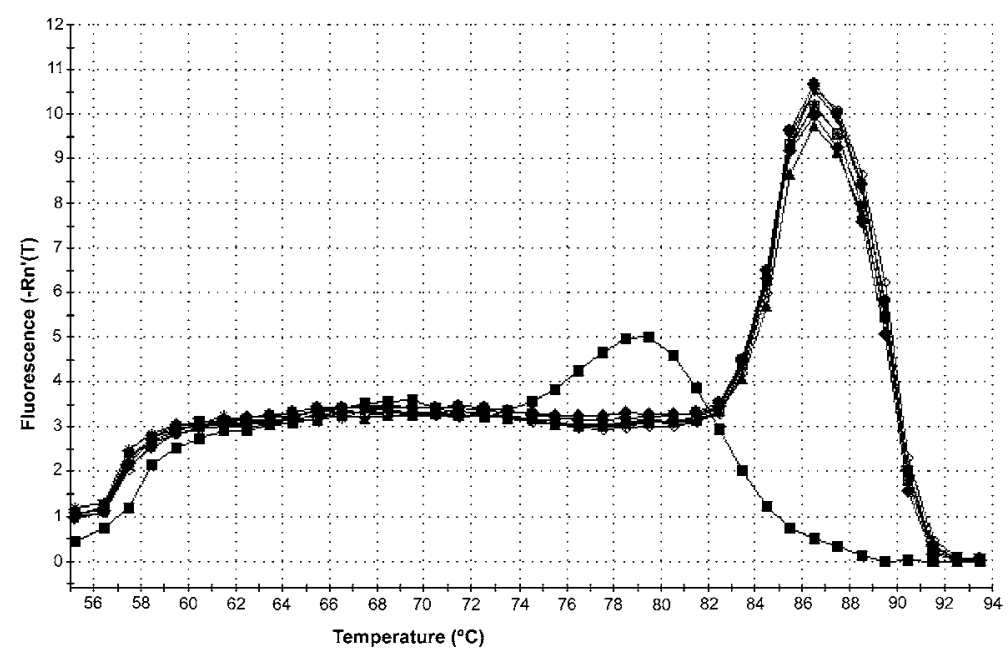

Figure 2 Dissociation curves are useful for determining the presence of multiple species in the sample

Every PCR product melts at a characteristic temperature, its $I_{\mathrm{m}}$ (melting temperature). A characteristic melting peak at the amplicon's $I_{\mathrm{m}}$ will usually distinguish it from amplification artifacts that melt at lower temperatures in broader peaks. In the $P C R$, these are typically primer-dimer artifacts or non-specific amplicons. For standard analysis, samples are first melted at $95^{\circ} \mathrm{C}$, and then equilibrated at $60^{\circ} \mathrm{C}$ before being slowly re-heated (dissociated) back to $95^{\circ} \mathrm{C}$. The centre of each peak reflects $I_{\mathrm{m}}$. The dissociation curves show typical primer-dimer formation. The specific product is shown with a $T_{\mathrm{m}}$ of $87^{\circ} \mathrm{C}$, whereas the primer-dimer $(\boldsymbol{\square})$ has a characteristically lower $I_{\mathrm{m}}$ of $79^{\circ} \mathrm{C}$. Primer-dimers will be most prevalent in NTC ('no template control') wells and sample wells containing low concentrations of template. 


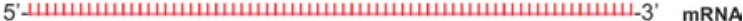

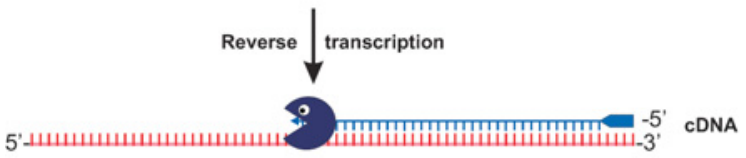

Hybridisation $\$ Polymerisation
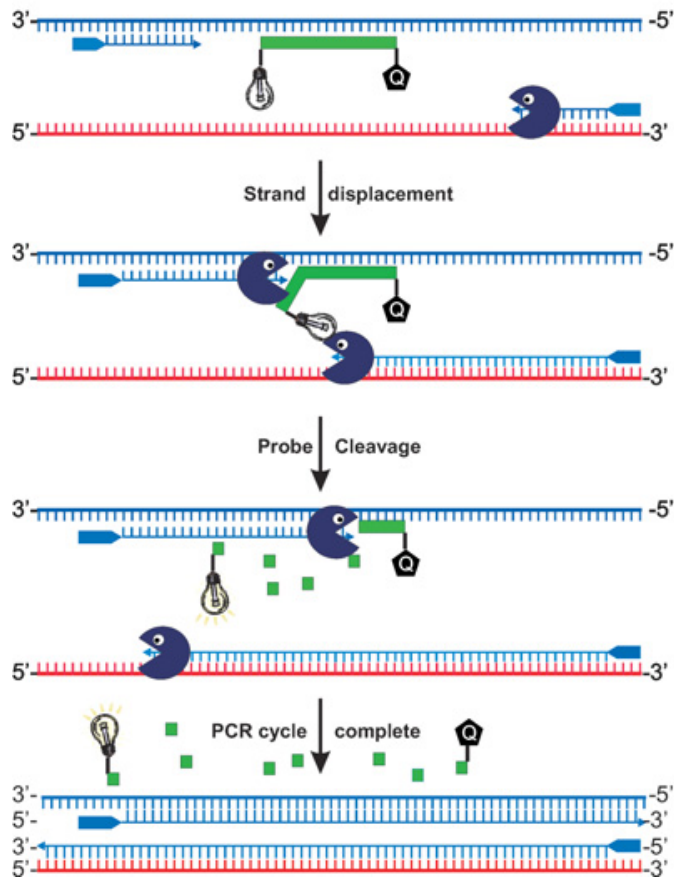

Figure 3 The principle of the $5^{\prime}$ nuclease (TaqMan) assay The RT step synthesizes a CDNA copy of the RNA template. After denaturation, primers and probe anneal to their targets. The probe contains a reporter dye at the $5^{\prime}$ end and a quencher $(Q)$ at its $3^{\prime}$ end. During the polymerization step, the $5^{\prime}$ nuclease activity of the Taq polymerase displaces and cleaves the probe. This physically separates the reporter dye and quencher dyes, resulting in reporter fluorescence. The increase in signal is directly proportional to the number of molecules released during that cycle. Accumulation of PCR products is detected directly by monitoring the increase in fluorescence of the reporter dye.

instances optimized conventional RT-PCR assays can be converted immediately into real-time assays [16]. An important disadvantage is that their specificity remains dependent on the specificity of the primers.

Probe-based chemistries make use of amplicon-specific fluorescent probes and a fluorescent signal is only generated if the probe hybridizes with its complementary target (Figure 3). Therefore probe-based chemistries introduce an additional level of specificity, in effect combining RT-PCR with a validation step previously carried out separately after the PCR.

Multiplexing permits the detection and differentiation of multiple targets, e.g. infectious agents or biomarkers, in a single tube at the same time. Although SYBR Green has been used for the simultaneous detection of enteric [17] and noroviruses [18], its scope is rather limited, not least because the preferential binding of SYBR Green to specific DNA sequences during amplification interferes with PCR kinetics [19]. Other non-specific chemistries $[20,21]$ are not any better at multiplexing than SYBR Green [22], but a recently developed non-probe-based chemistry promises to simplify multiplexing. It uses isoguanosine (iG) and isocytosine (iC) [23], which can pair only with each other. Upstream (sense) PCR primers are tagged at their $5^{\prime}$ ends with different fluorophores plus a single iso-dC ( $5^{\prime}$-methylisocytosine). A quencherlabelled iso-dG (2'-deoxyisoguanosine) is added to the amplification master mix and its incorporation opposite iso-dC results in increasing fluorescence quenching during amplification [24]. This technology is available as 'Plexor' from Promega. For multiplexing with probebased chemistries, probes are labelled with different fluorophores. There are three oligonucleotides per target, which can result in non-specific interactions between the primers and probes, and this demands careful assay design and reagent selection [25]. At the moment, quadruplex (quintuplex on the ABI 7500 and Stratagene MX3005P) assays are possible, but stretch the limits of the technology's capabilities [26]. Nevertheless, improved chemistries are constantly being developed and validated and it is clear that multiplex qRT-PCR will have an important role to play in clinical diagnostic assays [27].

It is also possible to carry out nested qPCR (quantitative PCR) assays [28] that consist of two separate amplification reactions primed by two sets of primers: the first reaction primed by two external primers is followed by a second reaction that uses two internal primers and a hybridization probe. Nested PCR assays can provide higher analytical sensitivity [29], and have been successfully applied to the early detection of the SARS (severe acute respiratory syndrome) virus [29,30]. However, increased susceptibility to contamination is an ever-present problem and the actual sensitivity and specificity of this method remains to be evaluated with studies involving a larger number of clinical specimens.

\section{QUANTIFICATION STRATEGIES}

Quantification can either be relative to an external standard curve or to one or more co-amplified internal control mRNAs [2]. The former is based on the use of a dilution series of an external standard, which can be used to generate a standard curve of $C_{t}$ (threshold cycle) against initial target copy number [31]. The copy numbers of unknown samples can be calculated from the linear regression of that standard curve, with the $y$-intercept giving the sensitivity and the slope giving the amplification efficiency. Standard curves can be constructed from PCR fragments, in vitro T7-transcribed 
sense RNA transcripts, single-stranded sense-strand synthetic oligodeoxyribonucleotides or from commercially available universal reference RNAs [32]. This strategy is most obviously useful for quantifying viral or tumour load in body fluids. The accuracy of absolute quantification depends entirely on the accuracy of the standards. In general, standard curves are highly reproducible and allow the generation of specific and reproducible results. However, external standards cannot detect or compensate for inhibitors that may be present in the samples.

Quantification relative to internal standards compares the $C_{\mathrm{t}}$ values from target RNAs to those of one or more internal reference genes and results are expressed as ratios of the target-specific signal to the internal reference. This produces a corrected relative value for the targetspecific RNA product that can be compared between samples and allows an estimate of the relative expression of target mRNA in those samples. It is crucial that the amplification efficiencies of target and reference are similar, since this directly affects the accuracy of any calculated expression result. Several models have been published that use different algorithms to correct for efficiency and claim to allow a more reliable estimation of the real expression ratio [33,34]. However, since the expression of most reference genes is regulated and their levels usually vary significantly with treatment or between individuals, relative quantification can be misleading [35]. Furthermore, if the relative levels of the reference and target RNAs vary by orders of magnitude, during amplification the former may have entered its plateau phase by the time a $C_{\mathrm{t}}$ for the target becomes apparent. Unless compensated for, this may interfere with the accurate quantification of the target RNA.

\section{QUALITY CONTROL ISSUES}

Optimization and consistency are as critical for obtaining reproducible results using qRT-PCR as they are for conventional methods [36]. qRT-PCR assays are significantly less variable than conventional RT-PCR protocols [37-39], which are subject to significant error [40,41]. However, since reproducibility is influenced by parameters such as distribution statistics [42], qRT-PCR data are less reproducible when working with very low copy numbers due to the stochastic sampling effects [43]. This emphasizes the importance of repetitive testing in clinical samples and one of the strengths of these assays is the ease with which it is possible to determine multiple $C_{\mathrm{t}}$ values for every sample, which encourages replicate determinations of the same sample and permits the application of statistical analyses to the quantification procedure.

Like any clinical diagnostic assay, qRT-PCR must be properly validated [44] and meet the criteria expected of any laboratory test applied in clinical medicine: (i) stan- dardization of the test across different laboratories; (ii) reproducibility of positive and negative predictive values; and (iii) reliable sensitivity and specificity. This involves the establishment of a set of quality protocols, the use of appropriate positive- and negative-control samples, and suitable analysis and reporting guidelines. Standardization is all-important $[5,45]$ and generates the robust and reliable results that are of critical importance for the management of patients entered into multicentre therapeutic trials [46].

A successful clinical diagnostic qRT-PCR assay requires careful consideration of several issues. (i) Optimal sample quality is a prerequisite to generate valid quantitative data [47]. Hence sample collection, preparation and transport and RNA extraction methods are all critical parameters in test performance and must be optimized. In general, extraction of RNA from blood and serum is relatively straightforward, whereas there are significant problems associated with the extraction of RNA from solid tumours, faeces and semen samples. The main problems are that RNA is easily degraded and that it is easy to co-purify inhibitors of the RT or PCR steps which will generate inconsistent results. (ii) Primer selection, especially of the reverse primer used in the RT-step, is critical since it affects the sensitivity of the RT-PCR assay [48]. The structure of the RNA target at the primerbinding site must be taken into account, as this affects the accessibility of the target to the primers. mRNA displays extensive secondary structure and selection of a primer binding site in a ds target site that is folded will result in a very inefficient assay. For RNA viruses there is the additional problem of different viral serotypes resulting in sequence variability and it may be necessary to use a nested RT-PCR assay with universal primers that bind to target sequences which are shared by all the serotypes, followed by a serotype-specific primer pair [49]. (iii) Regular calibration of the real-time instrument is crucial for obtaining consistent and accurate results. $C_{\mathrm{t}}$ is neither absolute nor invariant, but varies between assays carried out on different days with different reagents or on different instruments. This is because $C_{\mathrm{t}}$ depends on the instrument's threshold setting, which depends on background fluorescence, which in turn varies with different probes, chemistries, instruments and assay protocols. Therefore samples should not be compared by $C_{\mathrm{t}}$ values [11], but they should be converted into and reported as target copy numbers. (iv) Analytical sensitivity and specificity are critical parameters of any diagnostic qRT-PCR assay. Analytical sensitivity refers to the smallest number of RNA molecules that can be detected and distinguished from a zero result and is best calculated using a standard curve which defines the range of the assay. It is inappropriate to report results that lie significantly outside the upper and lower concentration of target defined by the standard curve. Analytical specificity is determined by identifying the percentage of 
samples without the target sequence that also generate a negative result. (v) There must be agreement between replicates within and between runs of the assay, as this provides important information about the reliability of the assay. Repeatability is measured as the amount of agreement between replicates tested in different runs in the same laboratory. Reproducibility is determined in several laboratories using the identical assay (protocol, reagents and controls). It is important to maintain the internal quality control by monitoring the assay for both parameters. If the assay is to be applied in another geographical region and/or population, it might be necessary to revalidate it under the new conditions as mutations or polymorphisms within the primer sites, especially at their 3 ' ends, will affect the performance of the assay and render the established validation no longer valid. It is also advisable to regularly sequence the selected genomic regions in the national isolates of the infectious agents. This is especially true for the primer sites to ensure that they remain stable, so that the validation of the assay cannot be questioned. (vi) False-positive results may arise either from product carryover from positive samples or, more commonly, from cross-contamination by PCR products from earlier experiments [50]. It is critically important to include negative controls, i.e. samples that are as similar to the test samples as possible but exclude the target. It is also advisable to include a no RT control that excludes the reverse transcriptase to exclude signal generation from contaminating DNA. Since falsenegative results in an optimized assay are mostly due to inhibitory effects and/or pipetting errors, it is important to always include a positive control with any qRT-PCR assay [51], ideally in the form of a standard curve. In addition, all samples should be tested for inhibition using a simple 'alien' assay [11] and any RNA preparations showing inhibition must be repurified.

A recent report [52] suggests that the variability of calibration curves is strongly influenced by the large variability of the measurements below 100 copies of a target gene. The authors [52] propose reducing the variance of the standard curve by not running the 1 and 10 copy standards and instead adding additional dilutions between 10 and 100 copies to the standard curve. The problem with this approach is that the highest dilutions provide information about the variability of the assay at those very low target copy numbers. qRT-PCR facilitates the inclusion of exact sensitivity controls on a per sample basis [53] and, clearly, PCR findings, positive or negative, are questionable if they are not supported by the associated data demonstrating the overall sensitivity of the assay applied [44]. Therefore it is acceptable to omit the highest dilutions if the target copy numbers are well above that threshold number. However, if the assay's specification is to detect 1-50 target copies, the standard curve must include the 1 and 10 copy dilutions. The authors also state that the reduced variance of the modified stan- dard curve makes it unnecessary to construct a calibration curve with each run and that running of the samples in duplicate is unnecessary. Running a standard curve with each assay immediately reveals any problem with that particular run and increases confidence when reporting negative results. The same argument applies to running samples in duplicate or, preferably, in triplicate and in this qRT-PCR is no different from any clinical diagnostic assay.

\section{APPLICATIONS}

\section{Viral pathogens}

RNA viruses constitute the most abundant group of pathogens in man, animals and plants and are classified according to their RNA genome. The low efficiency of proofreading and post-replicative repair activities of viral RNA polymerases results in high mutation rates, causing potential problems for an assay that relies on exquisite sequence specificity. Furthermore, populations of RNA viruses are extremely heterogeneous and RNA viral genomes are statistically defined but individually indeterminate. This has raised some concerns about the detrimental effect of primer-template mismatches on the polymerization efficiency and problems associated with geographically disparate reference sequences [54]. Nevertheless, the ability of qRT-PCR to generate accurate quantitative data has had a huge impact on the study of viral agents of infectious disease [55] and is helping to clarify disputed infectious disease processes and demonstrate links between specific viral sequences and patient clinical symptoms [56]. However, the lack of commercially available validated reagent kits for most viruses remains a major problem, as does the absence of standardization of the existing tests [57].

\section{Negative-strand RNA viruses}

The genome of negative-stranded RNA viruses consists of ss (single-stranded) 'antisense' RNA. These are transcribed into sense-strand mRNA by RNA-dependent RNA polymerases supplied by the viruses. This group includes the measles and mumps viruses and various viruses targeting the respiratory tract. Influenza virus types A and B, RSV (respiratory syncytial virus) and PIV (parainfluenza virus) types 1-4 cause respiratory infections of the upper and lower respiratory tract in infants and young children and are important causes of severe lower respiratory tract disease in elderly and immunocompromised patients, with significant morbidity and mortality. Since these respiratory viral pathogens cause very similar clinical symptoms, differential diagnosis of the pathogens is required. Although multiplex conventional RT-PCR assays have been developed, they tend to be less sensitive than individual assays [56] and require extensive post-PCR manipulation. For example, 
a recent report [58] describes the detection of the seven viruses in a combined RT-PCR/enzyme-linked amplicon hybridization assay; however, post-PCR processing involves a hybridization reaction, incubations, washes and spectrophotometric analysis. In contrast, a novel qRTPCR assay consists of two multiplex reactions, one detecting influenza $\mathrm{A}$ and $\mathrm{B}$ and RSV, the other one PIV $1-4$, and can generate a result within $6 \mathrm{~h}$. The assays display $100 \%$ specificity and detected virus in an additional $23 \%$ of samples [59]. Other real-time assays can differentiate between influenza A subtypes $[60,61]$ and RSV A and B [62] facilitating diagnosis, patient management and strain identification for vaccine production. A recent report [63] describes the specific detection of mumps virus not only in typical, but also in suspected cases which show only symptoms of meningitis or encephalitis.

\section{Positive-strand RNA viruses}

The genome of positive-stranded RNA viruses consists of ss 'sense' RNA and specifies its own RNA-dependent RNA polymerase. The RNA is translated by the host and then catalyses the synthesis of large numbers of antisense replicative intermediates that, in turn, serve as templates for the synthesis of a large number of mRNA molecules. This group includes the entero-, rhino- and corona-viruses. The SARS outbreak provides a textbook example of the importance and usefulness of qRT-PCR assays. SARS emerged in southern China in November 2002 and within months the disease had spread globally, affecting over 8000 patients in 29 countries with 774 fatalities. Although useful in the identification of the SARS virus, conventional RT-PCR assays were insufficiently sensitive to provide a diagnosis in the first few days after disease onset, the period during which laboratory diagnosis is most relevant for patient care. qRT-PCR-based diagnostic assays for the associated coronavirus were rapidly developed $[64,65]$ and improved to result in an assay with $100 \%$ specificity in samples collected from day $1-3$ of disease onset $[66,67]$. The assay's potential for high throughput was also of critical importance in areas with outbreaks of SARS in which large numbers of specimens had to be tested. In addition, the ability to quantify helped elucidate the pathogenesis of the disease, showing that, unlike other respiratory viral infections, viral load and rates of positivity of SARS coronavirus in the upper respiratory tract increased progressively to peak at around day 10 after disease onset [68]. Viral load was highest in specimens of the lower respiratory tract and was higher in nasopharyngeal aspirate than in throat swabs [69]. Faecal samples had very high viral loads towards the end of the first week of illness, and were the specimen of choice during the second week of disease [70].

The qRT-PCR assay also provides critical prognostic information for clinical management. It revealed that high viral load in the nasopharyngeal aspirate was associated with the occurrence of diarrhoea [71], the requirement for intensive care [72] and was an independent predictor of mortality [71]. qRT-PCR assays can now be used routinely to exclude SARS-associated coronavirus in patients hospitalized with respiratory symptoms even in the presence of other respiratory viruses [73]. qRTPCR assays have been designed that are specific for other positive-strand RNA viruses. A qRT-PCR assay developed for the clinical diagnosis of viral meningitis detects enterovirus in cerebrospinal fluid [74] and is significantly more sensitive than viral culture [75]. Another assay targets noroviruses, one of the most common aetiological agents of outbreaks of acute gastroenteritis [76]. This assay is four orders of magnitude more sensitive than a conventional RT-PCR assay with the same primer sets and as sensitive as nested conventional RTPCR [77].

\section{ds RNA viruses}

A third group of viruses has a segmented ds RNA genome, together with a RNA-dependent RNA polymerase that transcribes each of the ds RNA molecules into an mRNA. This group includes human rotaviruses, the most important aetiological agents of severe diarrhoeal illness of infants and young children worldwide. The classical clinical presentation of rotaviral infection is fever and vomiting, followed by non-bloody diarrhoea, which can lead to severe and potentially life-threatening dehydration. qRT-PCR assays based on SYBR Green [78] and TaqMan [79] chemistries have been developed and validated and are beginning to reveal the virus's epidemiology and pathogenesis [80].

\section{Retroviruses}

Viruses in this group, which include HIV and HTLV (human T-cell leukaemia virus), contain RNA-dependent DNA polymerases that copy their RNA genome into DNA, which integrates into the host genome. The hosts' normal transcription generates viral mRNA which is either translated or packaged into new virus particles. The concentration of HIV-1 RNA in the plasma of HIVinfected individuals is an important predictor of disease outcome and a marker of antiretroviral drug efficacy, allowing a specific analysis of treatment failure caused by emerging resistance to specific anti-retroviral compounds. The most sensitive FDA (Food and Drug Administration)-approved tests for HIV-1 RNA in plasma have detection limits of 50 copies/ml $[81,82]$ and treatment is generally considered successful if the level of viraemia can be reduced to below this level. However, reduction of the HIV-1 RNA load to $<50$ copies/ml does not guarantee long-term success, and a rebound of drug resistance can occur, implying that HIV-1 replication and evolution is continuing while patients are receiving 
therapy. Many patients whose levels of viraemia are suppressed to $<50$ copies $/ \mathrm{ml}$ have persistently detectable HIV-1 RNA [83]. Consequently, the development of qRT-PCR assays that can detect and quantify HIV-1 RNA in plasma down to 1 copy/ml promises a significant increase in the accuracy and clinical relevance of HIV testing [84].

The extreme sequence heterogeneity of HIV-1 poses a significant challenge to the efficient detection with nucleic-acid-based assays. Not only must the primers bind to regions that are conserved and not subject to rapid mutation, but also the probes used for specific chemistry assays must not hybridize to mutating sequences. This has led to the development of non-specific SYBR-Greenbased assays that rely on the use of melting curves to ensure that the obtained signal is specific [85]. These assays are better than branched-chain DNA assays in determining viral load [86], especially during the monitoring of HAART (highly active anti-retroviral therapy) treatment [87], and have a superior linearity over a wide concentration range [88]. The imminent release of the iso-C/G chemistry (see above) promises to enhance the performance of non-probe-dependent chemistries.

A multiplex real-time quantitative RT-PCR assay was developed for simultaneous detection, identification and quantification of $\mathrm{HBV}$ (hepatitis $\mathrm{B}$ virus), $\mathrm{HCV}$ (hepatitis C virus) and HIV-1 in plasma or serum samples. Genomic amplification of one virus was unaffected by the simultaneous amplification of the other two. Although competition between HCV and HIV-1 amplifications slightly affected the yield of HIV-1 amplification, quantification of a single virus was possible [89].

The IPCR (immunopolymerase chain reaction) assay combines the molecular recognition of antibodies with the high amplification capability of PCR [90], and realtime IPCR assays have been developed for the detection of cellular proteins such as VEGF (vascular endothelial growth factor), which is elevated in some cancers [91], and gliadins in patients with coeliac disease [92]. The procedure is similar to conventional ELISAs but allows for more sensitive detection. Instead of an enzyme, a DNA molecule is linked to the detection antibody and serves as a template for PCR. A real-time IPCR assay has been reported for the detection of HIV [93]. This assay detects the $\mathrm{p} 24$ protein of the virus, rather than viral nucleic acid. Since each virus particle contains thousands of molecules of $\mathrm{p} 24$, there is a greater amount of target to detect.

\section{Disease-specific marker detection}

Overall leukaemia-free survival rates in adult AL (acute leukaemia) depend on the diagnostic subtype of AL. These subtypes display significant differences in their clinical features, treatment responses, relapse sites and kinetics. Risk models are continuously amended with new prognostic factors, one of which is the evaluation of MRD (minimal residual disease), and the ability of qRTPCR to quantify MRD has resulted in its widespread adaptation for this purpose.

CML (chronic myeloid leukaemia) is characterized by the presence of the Philadelphia chromosome, a reciprocal $\mathrm{t}(9 ; 22)$ translocation that transposes the c-abl oncogene from chromosome $9 \mathrm{q} 34$ to the $B C R$ gene on chromosome 22q11. The rearranged $B C R-A B L$ gene is transcribed into a chimaeric mRNA, which in turn is translated into a $210 \mathrm{kD}$ fusion protein (p210) that mediates myeloid proliferation and transformation. Detection of this distinctive cytogenetic abnormality is the most important prognostic parameter for the assessment of complete remission and long-term survival. However, the sensitivity of cytogenetic analysis is low and, by the time disease is detectable, clinical relapse may be inevitable.

This has resulted in the development of RT-PCR-based monitoring methods that can detect all break points and can be performed on peripheral blood specimens [94]. The most comprehensive validation of a qRT-PCR assay for clinical diagnostic use tested 372 clinical specimens and 50 peripheral blood samples from patients not known to have any myeloproliferative disorders. The assay was shown to be $100 \%$ specific, and able to detect a single copy of a target spiked into negative RNA. The betweenrun reproducibility had a $\mathrm{CV}$ (coefficient of variance) of $12.3 \%$, and within-run reproducibility had a CV of $13.8 \%$ [95], helping replace conventional RT-PCR assays, even nested ones [96], as the most sensitive and reliable method for molecular follow-up [97,98].

Its capacity for accurate quantification is a significant advantage of qRT-PCR assays, since mere detection of MRD does not permit reliable prediction of the course of disease in individual patients [99], whereas its quantification correlates with disease stage [100]. Consequently, monitoring of the dynamics of residual disease in CML patients by serial qRT-PCR performed at regular intervals predicts impending clinical relapse in patients who are still in haematological and cytogenetic remission and is useful in guiding clinical therapeutic decisions $[101,102]$.

Detection of disease-specific translocations is also at the core of strategies aimed at assessing the response of individual patients to therapeutic intervention [103]. Conventional RT-PCR results reporting on treatment response in patients who had undergone allogeneicmatched sibling SCT (stem cell transplantation) were ambiguous, with some reports identifying subgroups of patients at risk of disease recurrence, and others detecting no association between PCR positivity and subsequent relapse $[104,105]$. Conversely, qRT-PCR assays quantifying levels of BCR-ABL RNA showed no such ambiguity and were clearly able to identify patients likely to relapse after bone marrow transplant [106-109], 
making this technology the method of choice for early therapeutic decision making [110].

qRT-PCR is also penetrating clinical diagnostic assays designed to detect other haematological malignancies. The presence of a transcript specifying a BCR-ABL fusion protein of $190 \mathrm{kDa}$ in ALL (acute lymphoblastic leukaemia) usually indicates poor prognosis and warrants haematopoietic SCT [111]. A simple multiplex assay distinguishing between the transcript variants has been described recently [112]. APL (acute promyelocytic leukaemia) is characterized by a reciprocal translocation between chromosomes 15 and 17 , resulting in the creation of a hybrid gene $(P M L / R A R)$ that is thought to mediate leukaemogenesis. A multiplex qRT-PCR assay has been designed that is capable of quantifying and simultaneously identifying transcript variants. Three different PML/RAR fusion transcripts forms have been identified in APL and a treatment response may depend upon which fusion transcript form they express [113].

\section{Disease-associated detection}

In contrast with haematological malignancies, solid tumours are not characterized by universal molecular markers. Nevertheless, 'molecular staging' using RT-PCR to amplify tissue-specific mRNA has long been viewed as a possible solution for increasing the accuracy of postoperative staging and has been evaluated extensively in the molecular assessment of tumour stage and disease recurrence [114,115]. However, there are significant technical and conceptual limitations [116,117] that hold back its adaptation into clinical practice [118] and it continues to constitute a 'proof of principle' rather than robust and reliable clinical assay [119]. The introduction of significant variability by the RT step makes it problematic to delineate universal biologically relevant quantitative 'cut-off' points [10] and the lack of standardized protocols results in lack of reproducibility between laboratories [120]. However, most crucially, there are no disease-specific markers uniquely associated with any solid cancer. Hence the use of tissue-specific markers, which are presumed to detect the presence of cancer cells in patients' blood, bone marrow or LN (lymph nodes). Unfortunately, it is unclear just how tissue-specific these markers are [116].

Colorectal cancer provides a good paradigm of the difficulties encountered when attempting to use molecular techniques as diagnostic assays [119]. Although the detection of tumour invasion in draining LN by histopathological staging is a poor prognostic factor, there is considerable prognostic heterogeneity within each tumour stage [121]. Achieving accurate stratification of individuals into prognostic groups within a given stage is assuming increasing importance with the recent emergence of more effective adjuvant chemotherapy protocols that have had a positive impact on patient survival [122].
There have been numerous studies reporting the detection of mRNA markers such as CEA (carcinoembryonic antigen), cytokeratins (ck), mucins, CD44 and GCC (guanylate cyclase $\mathrm{C}$ ) in different tissue compartments and attempting to assess their prognostic significance [123]. One report [124] suggests that it is possible to distinguish histologically positive LN from histologically negative ones by counting the number of CEA-expressing cells. However, there was significant overlap between the two groups and cell numbers were calculated relative to a CEA-expressing cell line, ignoring inter-sample or inter-patient variation of CEA mRNA levels. A second study [125] calculated CEA copy numbers in LN relative to 18S RNA levels, and used cut-off levels to suggest that high CEA mRNA levels might be predictive of distant recurrence. A third study [126] also concluded that quantification of CEA mRNA levels in LN from patients with advanced colorectal cancer yielded prognostic information. Unfortunately, quantifying the amount of an mRNA value does not allow the calculation of the number of circulating tumour cells, since the expression of most genes varies by several orders of magnitude between tumours in different individuals and often varies in the tumour of the same individual [127]. Also, none of these authors discussed how to implement a relative quantification assay in practice.

In complete contrast, studies using both conventional [128] and real-time [116] RT-PCR reported the detection of CEA mRNA in up to $85 \%$ of control LN, with significant overlap of CEA copy numbers between histologically involved and uninvolved LN. There was no correlation between CEA copy numbers and prognosis, suggesting that a CEA-based assay is unable to identify patients at risk of distant disease recurrence. At least there is a rationale for attempting to detect occult disease in LN: histological detection of occult disease during staging is an important prognostic indicator. This is not the case for blood. Nevertheless, some reports suggest that CEA mRNA levels in the blood of colorectal cancer patients are associated with disease stage [129] and may be of prognostic value $[130,131]$. These contrast with others that question its specificity and suggest that peripheral blood is not a suitable compartment for detection of tumour cells $[117,120,128,132]$, or advocate analysis of yet another tissue compartment [133]. Similar contradictory results have been reported for other tissuespecific markers [119]. This discordance is typical and, when results are analysed in detail, there is little agreement on the specificity of the various markers, and there is a significant percentage of patients that test positive for the marker in question, yet survive for 5 years, or do not test positive for the marker, yet die within 5 years $[116,117]$. Characteristically, the usual conclusion is that the respective markers have not yet been evaluated sufficiently to recommend their inclusion in a clinical assay [134]. This is not surprising when considering 
that blood, bone marrow or LN sampling represents a single snapshot of a complex and dynamic process and that few of the large number of cancer cells shed from a primary tumour ever form metastatic tumours [135]. Consequently, despite this vast effort, PCR-based techniques have still not been validated clinically in prospective studies and the presence of circulating tumour cells cannot be considered a reliable prognostic indicator.

This suggests a conceptual flaw underlying the attempts to use RT-PCR assays to allow prediction of successful distant metastasis, as it is based on a simplistic view of the biology and kinetics of tumour cell traffic through the lymphatic and systemic circulation and subsequent metastasis development. Instead RT-PCR may simply be detecting cells of no biological significance [136] and variability in survival within each staging category probably reflects not only the inaccuracy of detecting occult residual disease, but also a lack of understanding of the sequestration, release and subsequent trafficking of the tumour cell in both the lymphatic and systemic circulation. None of the qRT-PCR assays address the question of the biological relevance of detecting tumour cells in blood or LN and do not provide any information about their metastatic potential or take into account the role of patient genotype in allowing or suppressing metastasis. Animal models suggest that only $0.01 \%$ of cells circulating in the blood ultimately develop into a metastatic site [137], and in humans the likelihood of tumour cells seeding to become metastases is also very low [138]. Furthermore, the genotype of LN metastases differs from that of the main clone in the primary tumour in $>50 \%$ of patients, with a significant minority displaying a genotype not detected in the primary tumour at all [138]. In addition, humans themselves are genetically polymorphic, and the outcome of metastasis depends on the interplay of tumour cells with various host factors, including the organ microenvironment, which can influence the biology of cancer growth, angiogenesis and metastasis [139]. Therefore it is not surprising that the detection of occult disease is unlikely to have prognostic value.

\section{RT-PCR-ASSOCIATED PROBLEMS}

There are several technical causes that can result in ambiguous data, especially when targeting disease-associated markers [11].

\section{RNA purification}

Clinical samples from which RNA is extracted tend to be disparate and include blood and other body fluids as well as solid biopsies obtained during endoscopy, postsurgery, post-mortem and from archival materials. Naked RNA is extremely susceptible to degradation by endogenous RNases (ribonucleases) that are present in all living cells. Therefore the key to the successful isolation of high-quality RNA and to the reliable and meaningful comparison of qRT-PCR data is to ensure that neither endogenous nor exogenous RNases are introduced during the extraction procedure [140].

Recent reports suggest that RNA extracted from FFPE (formalin-fixed paraffin-embedded) archival materials can be successfully quantified by qRT-PCR assays. Between $60 \%$ [141] and $84 \%$ (100\% of samples less than 10 years old) [142] of templates can be amplified by RT-PCR, and it is possible to quantify mRNA expression levels [143]. Formalin-fixed tissues are ideal for retrospective clinical studies of disease mechanisms and, as the use of PCR technology has become more common in molecular testing, it has enhanced the clinical utility of these tissues. This is important, since such studies have the potential to enable the correlation of molecular findings with the patient's response to treatment and eventual clinical outcome. qRT-PCR assays, with their amplicon lengths of below $100 \mathrm{bp}$, are ideally placed to amplify the usually degraded RNA from these archival samples whose average size is 200-250 nucleotides. However, care must be taken when interpreting the results obtained from archival material, as gene expression profiles from FFPE samples do not correlate exactly with the profiles generated from the corresponding frozen samples $\left(r^{2}=0.69\right)$ [144]. The same authors report that, although 64 genes were differentially expressed in matching fresh-frozen normal colon and cancer samples, only 38 were in the corresponding FFPE samples. Furthermore, only 28 of these genes were in common. Thus any results obtained using FFPE samples require independent experimental determination [145], but also may underestimate or report misleading changes in gene expression patterns.

\section{cDNA synthesis}

Priming of the cDNA reaction from the RNA template can be carried out using random primers, oligo(dT), a mixture of both or target-specific primers. The choice of primer can cause marked variation in calculated mRNA copy numbers [146] and results obtained using the different methods are not comparable [147]. It is also little appreciated that cDNA synthesis can be primed efficiently without addition of any primer at all [148].

\section{Random primers}

This method yields the most cDNA but, since transcripts originate from multiple points along the transcript, more than one cDNA transcript is produced per original target. Furthermore, the majority of cDNA synthesized from total RNA will be ribosomal RNA-derived and may compete with a target that is present at very low levels. As the $T_{\mathrm{m}}$ of random primers is low, they cannot be used with thermostable RT enzymes without a low temperature 
pre-incubation step. This is the least satisfactory method of synthesizing cDNA.

\section{oligo(dT)}

cDNA synthesis using oligo(dT) is more specific than random priming, as it will not result in the priming from rRNA. It is the best method to use when the aim is to obtain a faithful cDNA representation of the mRNA pool, although it will not prime any RNAs that lack a polyA $^{+}$(polyadenylated) tail. In addition, oligo(dT) priming requires very high-quality RNA that is fulllength, and hence is not a good choice for priming from RNA that is likely to be fragmented, such as that obtained from FFPE archival material. Furthermore, the RT may fail to reach the primer/probe-binding site if secondary structures exist or if the primer/probe-binding site is at the extreme $5^{\prime}$ end of a long mRNA. It is possible to mix random primers and oligo $(\mathrm{dT})$; however, this may exacerbate the problems of accurate quantification, as the variable priming of the random oligonucleotides is likely to introduce variability.

\section{Target-specific primers}

Target-specific primers synthesize the most specific cDNA and provide the most sensitive method of quantification [149]. Their main disadvantage is that they require separate priming reactions for each target, which is wasteful if only limited amounts of RNA are available.

\section{Inhibitors}

The co-purification of inhibitors of the RT-PCR during template preparation can present a serious problem to accurate and reproducible quantification of mRNA levels [150]. Common inhibitors include various components of body fluids and reagents encountered in clinical and forensic science (e.g. haemoglobin and urea), food constituents (e.g. organic and phenolic compounds, and fats) and environmental compounds (e.g. humic acids and heavy metals) [151]. In addition, factors such as DNA fragmentation [152] and the presence of residual anticoagulant heparin [153] or proteinase $\mathrm{K}$ digested haem compounds such as haemoglobin [154] will negatively affect PCR efficiency. The problem with this type of inhibitor is that it makes the comparison of qRT-PCR results from different patients or different samples from the same patient impossible as it results in different amplification efficiencies and hence $C_{\mathrm{t}}$ values of the same target from different patients. Worryingly, laboratory plasticware has been identified as one potential source of PCR inhibitors [155]. It is also important to remember that reagents can have a significant effect on assay reproducibility, with lot-to-lot variation an essential consideration [156]. Different polymerases display variable sensitivity to the presence of inhibitors such as blood, ions or biological samples [157-159]. Thus the PCR-inhibiting effect of various components in bio- logical samples can, to some extent, be eliminated by the use of the appropriate thermostable DNA polymerase.

\section{Other considerations}

The variability of RT-PCR results obtained from identical samples assayed in different laboratories continues to be a problem [160]. The single most likely source of data variation is due to variability introduced by the person carrying out the experiment. Since there are so many steps involved in going from a tissue sample to a quantitative result, it is not surprising that this is so. Other sources of variability are the reagents, especially the probe and RT, and it is essential to include appropriate controls with every run.

The recent introduction of robots capable of extracting RNA from tissue samples and pipetting very small volumes promises to address two bottlenecks, those of template preparation and the dispensing of reagents. It should also reduce the variability and contamination observed when different operators prepare multiple templates [161].

\section{SUMMARY AND CONCLUSION}

Some technologies arrive at a time that is 'just right', and advances in chemistries and instrumentation make qRT-PCR a technology whose time has come [162]. This is reflected in the increasingly important role it plays in clinical diagnosis, in particular when used for the assessment of viral load and the analysis of diseasespecific translocation products in haematological malignancies. It is also clear that appropriate application, quality control and standardization are issues that must be addressed and it is vital to consider each stage of the experimental protocol, starting with the laboratory setup, proceeding through sample acquisition and template preparation, and the RT and PCR steps. Only if every one of these stages is properly validated is it possible to obtain reliable quantitative data. Of course, choice of chemistries, primers and probes, and instruments must be appropriate to whatever is being quantified. Finally, data must be interpreted, and this remains a real problem. Significant technical problems remain, mainly associated with the conversion into cDNA and subsequent amplification of the RNA template.

These problems hint at a next generation of assays that address the problems that are inherent to any RT-PCR. Developments in microfluidics are already allowing the amplification of target nucleic acid from nanolitres of sample [163]. However, the ideal assay would eliminate the need to amplify a target and it is likely that real-time RT-PCR will eventually be replaced by methods capable of direct analysis of single biological molecules. One such single-molecule fluorescence detection technology is fluorescence correlation spectroscopy, which 
detects expression by hybridizing two dye-labelled DNA probes to a selected target molecule, which can be either DNA or RNA in solution. The subsequent dual-colour cross-correlation analysis allows the quantification of the biomolecule of interest in absolute numbers down to target concentrations of less than $10^{-12} \mathrm{M}$ [164]. Combined with single molecule sequencing [165], this will eventually permit RNA identification as well as distortion-free quantification. That is the future. For now, qRT-PCR assays, when carried out appropriately, are the method of choice for RNA detection and quantification.

\section{ACKNOWLEDGMENTS}

S. A. B. wishes to thank the charity Bowel \& Cancer Trust for supporting some of the work described in this review.

\section{REFERENCES}

1 Gibson, U. E., Heid, C. A. and Williams, P. M. (1996) A novel method for real time quantitative RT-PCR. Genome Res. 6, 995-1001

2 Bustin, S. A. (2000) Absolute quantification of mRNA using real-time reverse transcription polymerase chain reaction assays. J. Mol. Endocrinol. 25, 169-193

3 Ginzinger, D. G. (2002) Gene quantification using real-time quantitative PCR: an emerging technology hits the mainstream. Exp. Hematol. 30, 503-512

4 Nashed, A. L., Rao, K. W. and Gulley, M. L. (2003) Clinical applications of BCR-ABL molecular testing in acute leukemia. J. Mol. Diagn. 5, 63-72

5 Niesters, H. G. (2004) Molecular and diagnostic clinical virology in real time. Clin Microbiol. Infect. 10, 5-11

6 Bianchi, D. W. (2004) Circulating fetal DNA: its origin and diagnostic potential - a review. Placenta 25 (Suppl. A), S93-S101

7 Ozoemena, L. C., Minor, P. D. and Afzal, M. A. (2004) Comparative evaluation of measles virus specific TaqMan PCR and conventional PCR using synthetic and natural RNA templates. J. Med. Virol. 73, 79-84

8 Orlando, C., Pinzani, P. and Pazzagli, M. (1998) Developments in quantitative PCR. Clin. Chem. Lab. Med. 36, 255-269

9 Halford, W. P., Falco, V. C., Gebhardt, B. M. and Carr, D. J. (1999) The inherent quantitative capacity of the reverse transcription-polymerase chain reaction. Anal. Biochem. 266, 181-191

10 Bustin, S. A. (2002) Quantification of mRNA using real-time reverse transcription PCR (RT-PCR): trends and problems. J. Mol. Endocrinol. 29, 23-39

11 Bustin, S. A. and Nolan, T. (2004) Pitfalls of quantitative reverse transcription polymerase chain reaction. J. Biomol. Tech. 15, 155-166

12 Jung, R., Soondrum, K., Kruger, W. and Neumaier, M. (2001) Detection of micrometastasis through tissuespecific gene expression: its promise and problems. Recent Results Cancer Res. 158, 32-39

13 Wittwer, C. T., Herrmann, M. G., Moss, A. A. and Rasmussen, R. P. (1997) Continuous fluorescence monitoring of rapid cycle DNA amplification. BioTechniques 22, 130-138

14 Morrison, T. B., Weis, J. J. and Wittwer, C. T. (1998) Quantification of low-copy transcripts by continuous SYBR Green I monitoring during amplification. BioTechniques 24, 954-962

15 Ririe, K. M., Rasmussen, R. P. and Wittwer, C. T. (1997) Product differentiation by analysis of DNA melting curves during the polymerase chain reaction.

Anal. Biochem. 245, 154-160
16 Tan, B. H., Lim, E. A., Liaw, J. C., Seah, S. G. and Yap, E. P. (2004) Diagnostic value of real-time capillary thermal cycler in virus detection. Expert Rev. Mol. Diagn. $4,219-230$

17 Beuret, C. (2004) Simultaneous detection of enteric viruses by multiplex real-time RT-PCR. J. Virol. Methods $115,1-8$

18 Richards, G. P., Watson, M. A., Fankhauser, R. L. and Monroe, S. S. (2004) Genogroup I and II noroviruses detected in stool samples by real-time reverse transcription-PCR using highly degenerate universal primers. Appl. Environ. Microbiol. 70, 7179-7184

19 Giglio, S., Monis, P. T. and Saint, C. P. (2003) Demonstration of preferential binding of SYBR Green I to specific DNA fragments in real-time multiplex PCR. Nucleic Acids Res. 31, e136

20 Bengtsson, M., Karlsson, H. J., Westman, G. and Kubista, M. (2003) A new minor groove binding asymmetric cyanine reporter dye for real-time PCR. Nucleic Acids Res. 31, e45

21 Nazarenko, I., Lowe, B., Darfler, M., Ikonomi, P., Schuster, D. and Rashtchian, A. (2002) Multiplex quantitative PCR using self-quenched primers labeled with a single fluorophore. Nucleic Acids Res. 30, E37

22 Varga, A. and James, D. (2005) Detection and differentiation of Plum pox virus using real-time multiplex PCR with SYBR Green and melting curve analysis: a rapid method for strain typing. J. Virol. Methods 123, 213-220

23 Johnson, S. C., Sherrill, C. B., Marshall, D. J., Moser, M. J. and Prudent, J. R. (2004) A third base pair for the polymerase chain reaction: inserting isoC and isoG. Nucleic Acids Res. 32, 1937-1941

24 Sherrill, C. B., Marshall, D. J., Moser, M. J., Larsen, C. A., Daude-Snow, L. and Prudent, J. R. (2004) Nucleic acid analysis using an expanded genetic alphabet to quench fluorescence. J. Am. Chem. Soc. 126, 4550-4556

25 Elnifro, E. M., Ashshi, A. M., Cooper, R. J. and Klapper, P. E. (2000) Multiplex PCR: optimization and application in diagnostic virology. Clin. Microbiol. Rev. 13, 559-570

26 Grace, M. B., McLeland, C. B., Gagliardi, S. J., Smith, J. M., Jackson, III, W. E. and Blakely, W. F. (2003) Development and assessment of a quantitative reverse transcription-PCR assay for simultaneous measurement of four amplicons. Clin. Chem. 49, 1467-1475

27 Salto-Tellez, M., Shelat, S. G., Benoit, B. et al. (2003) Multiplex RT-PCR for the detection of leukemiaassociated translocations: validation and application to routine molecular diagnostic practice. J. Mol. Diagn. 5, 231-236

28 Max, N., Wolf, K., Thiel, E. and Keilholz, U. (2002) Quantitative nested real-time RT-PCR specific for tyrosinase transcripts to quantitate minimal residual disease. Clin. Chim. Acta 317, 39-46

29 Jiang, S. S., Chen, T. C., Yang, J. Y. et al. (2004) Sensitive and quantitative detection of severe acute respiratory syndrome coronavirus infection by real-time nested polymerase chain reaction. Clin. Infect. Dis. 38, 293-296

30 Lau, L. T., Fung, Y. W., Wong, F. P. et al. (2003) A realtime PCR for SARS-coronavirus incorporating target gene pre-amplification. Biochem. Biophys. Res. Commun. 312, 1290-1296

31 Ke, L. D., Chen, Z. and Yung, W. K. (2000) A reliability test of standard-based quantitative PCR: exogenous vs endogenous standards. Mol. Cell. Probes 14, 127-135

32 Pfaffl, M. W. and Hageleit, M. (2001) Validities of mRNA quantification using recombinant RNA and recombinant DNA external calibration curves in real-time RT-PCR. Biotechnol. Lett. 23, 275-282

33 Pfaffl, M. W. (2001) A new mathematical model for relative quantification in real-time RT-PCR. Nucleic Acids Res. 29, E45

34 Liu, W. and Saint, D. A. (2002) Validation of a quantitative method for real time PCR kinetics. Biochem. Biophys. Res. Commun. 294, 347-353

35 Hocquette, J. F. and Brandstetter, A. M. (2002) Common practice in molecular biology may introduce statistical bias and misleading biological interpretation. J. Nutr. Biochem. 13, 370-377 
36 Bustin, S. A. (2004) A-Z of Quantitative PCR, IUL Press

37 Heid, C. A., Stevens, J., Livak, K. J. and Williams, P. M. (1996) Real time quantitative PCR. Genome Res. 6 986-994

38 Gerard, C. J., Olsson, K., Ramanathan, R., Reading, C. and Hanania, E. G. (1998) Improved quantitation of minimal residual disease in multiple myeloma using real-time polymerase chain reaction and plasmid-DNA complementarity determining region III standards. Cancer Res. 58, 3957-3964

39 Wittwer, C. T., Ririe, K. M., Andrew, R. V., David, D. A., Gundry, R. A. and Balis, U. J. (1997) The LightCycler: a microvolume multisample fluorimeter with rapid temperature control. BioTechniques 22, 176-181

40 Souaze, F., Ntodou-Thome, A., Tran, C. Y., Rostene, W. and Forgez, P. (1996) Quantitative RT-PCR: limits and accuracy. BioTechniques 21, 280-285

41 Zhang, J., Desai, M., Ozanne, S. E., Doherty, C., Hales, C. N. and Byrne, C. D. (1997) Two variants of quantitative reverse transcriptase PCR used to show differential expression of $\alpha$-, $\beta$ - and $\gamma$-fibrinogen genes in rat liver lobes. Biochem. J. 321, 769-775

42 de Vries, T. J., Fourkour, A., Punt, C. J. et al. (1999) Reproducibility of detection of tyrosinase and MART-1 transcripts in the peripheral blood of melanoma patients: a quality control study using real-time quantitative RT-PCR. Br. J. Cancer 80, 883-891

43 Peccoud, J. and Jacob, C. (1996) Theoretical uncertainty of measurements using quantitative polymerase chain reaction. Biophys. J. 71, 101-108

44 Afzal, M. A., Osterhaus, A. D., Cosby, S. L. et al. (2003) Comparative evaluation of measles virus-specific RT-PCR methods through an international collaborative study. J. Med. Virol. 70, 171-176

45 Niesters, H. G. (2001) Quantitation of viral load using real-time amplification techniques. Methods 25, 419-429

46 Gabert, J., Beillard, E., van der Velden, V. H. et al. (2003) Standardization and quality control studies of 'real-time' quantitative reverse transcriptase polymerase chain reaction of fusion gene transcripts for residual disease detection in leukemia: a Europe Against Cancer program. Leukemia 17, 2318-2357

47 Muller, M. C., Hordt, T., Paschka, P. et al. (2004) Standardization of preanalytical factors for minimal residual disease analysis in chronic myelogenous leukemia. Acta Haematol. 112, 30-33

48 Raengsakulrach, B., Nisalak, A., Maneekarn, N. et al. (2002) Comparison of four reverse transcriptionpolymerase chain reaction procedures for the detection of dengue virus in clinical specimens. J. Virol. Methods 105, 219-232

49 Yenchitsomanus, P. T., Sricharoen, P., Jaruthasana, I. et al. (1996) Rapid detection and identification of dengue viruses by polymerase chain reaction (PCR). Southeast Asian J. Trop. Med. Public Health 27, 228-236

50 Kwok, S. and Higuchi, R. (1989) Avoiding false positives with PCR. Nature (London) 339, 237-238

51 Monpoeho, S., Coste-Burel, M., Costa-Mattioli, M. et al. (2002) Application of a real-time polymerase chain reaction with internal positive control for detection and quantification of enterovirus in cerebrospinal fluid. Eur. J. Clin. Microbiol. Infect. Dis. 21, 532-536

52 Rothlisberger, B., Herklotz, R., Hergersberg, M., Stricker, C., Bargetzi, M. and Huber, A. R. (2004) Quantitative monitoring of BCR-ABL transcriptsuggestion of a simplified approach considering inaccuracy of measurement and calibration. Leuk. Lymphoma 45, 1119-1121

53 Max, N., Willhauck, M., Wolf, K. et al. (2001) Reliability of PCR-based detection of occult tumour cells: lessons from real-time RT-PCR. Melanoma Res. 11, 371-378

54 Mullan, B., Sheehy, P., Shanahan, F. and Fanning, L. (2004) Do Taq-generated RT-PCR products from RNA viruses accurately reflect viral genetic heterogeneity? J. Viral Hepat. 11, 108-114

55 Schutten, M. and Niesters, H. G. (2001) Clinical utility of viral quantification as a tool for disease monitoring. Expert Rev. Mol. Diagn. 1, 153-162
56 Mackay, I. M., Arden, K. E. and Nitsche, A. (2002) Real-time PCR in virology. Nucleic Acids Res. 30, 1292-1305

57 Kao, C. L., King, C. C., Chao, D. Y., Wu, H. L. and Chang, G. J. (2005) Laboratory diagnosis of dengue virus infection: current and future perspectives in clinical diagnosis and public health. J. Microbiol. Immunol. Infect. 38, 5-16

58 Syrmis, M. W., Whiley, D. M., Thomas, M. et al. (2004) A sensitive, specific, and cost-effective multiplex reverse transcriptase-PCR assay for the detection of seven common respiratory viruses in respiratory samples. J. Mol. Diagn. 6, 125-131

59 Templeton, K. E., Scheltinga, S. A., Beersma, M. F., Kroes, A. C. and Claas, E. C. (2004) Rapid and sensitive method using multiplex real-time PCR for diagnosis of infections by influenza a and influenza $B$ viruses, respiratory syncytial virus, and parainfluenza viruses 1,2 , 3, and 4. J. Clin. Microbiol. 42, 1564-1569

60 van Elden, L. J., Nijhuis, M., Schipper, P., Schuurman, R. and van Loon, A. M. (2001) Simultaneous detection of influenza viruses $\mathrm{A}$ and $\mathrm{B}$ using real-time quantitative PCR. J. Clin. Microbiol. 39, 196-200

61 Stone, B., Burrows, J., Schepetiuk, S. et al. (2004) Rapid detection and simultaneous subtype differentiation of influenza A viruses by real time PCR. J. Virol. Methods $117,103-112$

62 Kuypers, J., Wright, N. and Morrow, R. (2004) Evaluation of quantitative and type-specific real-time RT-PCR assays for detection of respiratory syncytial virus in respiratory specimens from children. J. Clin. Virol. 31, 123-129

63 Uchida, K., Shinohara, M., Shimada, S. et al. (2005) Rapid and sensitive detection of mumps virus RNA directly from clinical samples by real-time PCR. J. Med. Virol. 75, 470-474

64 Poon, L. L., Chan, K. H., Wong, O. K. et al. (2003) Early diagnosis of SARS coronavirus infection by real time RT-PCR. J. Clin. Virol. 28, 233-238

65 Poon, L. L., Wong, O. K., Chan, K. H. et al. (2003) Rapid diagnosis of a coronavirus associated with severe acute respiratory syndrome (SARS). Clin. Chem. 49, 953-955

66 Hui, R. K., Zeng, F., Chan, C. M., Yuen, K. Y., Peiris, J. S. and Leung, F. C. (2004) Reverse transcriptase PCR diagnostic assay for the coronavirus associated with severe acute respiratory syndrome. J. Clin. Microbiol. 42, 1994-1999

67 Poon, L. L., Wong, B. W., Chan, K. H. et al. (2004) A one step quantitative RT-PCR for detection of SARS coronavirus with an internal control for PCR inhibitors. J. Clin. Virol. 30, 214-217

68 Peiris, J. S., Chu, C. M., Cheng, V. C. et al. (2003) Clinical progression and viral load in a community outbreak of coronavirus-associated SARS pneumonia: a prospective study. Lancet 361, 1767-1772

69 Drosten, C., Gunther, S., Preiser, W. et al. (2003) Identification of a novel coronavirus in patients with severe acute respiratory syndrome. New Engl. J. Med. 348, 1967-1976

70 Poon, L. L., Chan, K. H., Wong, O. K. et al. (2004) Detection of SARS coronavirus in patients with severe acute respiratory syndrome by conventional and real-time quantitative reverse transcription-PCR assays. Clin. Chem. 50, 67-72

71 Cheng, V. C., Hung, I. F., Tang, B. S. et al. (2004) Viral replication in the nasopharynx is associated with diarrhea in patients with severe acute respiratory syndrome. Clin. Infect. Dis. 38, 467-475

$72 \mathrm{Ng}$, E. K., Ng, P. C., Hon, K. L. et al. (2003) Serial analysis of the plasma concentration of SARS coronavirus RNA in pediatric patients with severe acute respiratory syndrome. Clin. Chem. 49, 2085-2088

73 Rohde, G., Borg, I., Arinir, U. et al. (2004) Evaluation of a real-time polymerase-chain reaction for severe acute respiratory syndrome (SARS) associated coronavirus in patients with hospitalised exacerbation of COPD. Eur. J. Med. Res. 9, 505-509 
74 Verstrepen, W. A., Kuhn, S., Kockx, M. M., Van De Vyvere, M. E. and Mertens, A. H. (2001) Rapid detection of enterovirus RNA in cerebrospinal fluid specimens with a novel single-tube real-time reverse transcription-PCR assay. J. Clin. Microbiol. 39, 4093-4096

75 Verstrepen, W. A., Bruynseels, P. and Mertens, A. H. (2002) Evaluation of a rapid real-time RT-PCR assay for detection of enterovirus RNA in cerebrospinal fluid specimens. J. Clin. Virol. 25 (Suppl.), 39-43

76 Pang, X., Lee, B., Chui, L., Preiksaitis, J. K. and Monroe, S. S. (2004) Evaluation and validation of real-time reverse transcription-pcr assay using the LightCycler system for detection and quantitation of norovirus. J. Clin. Microbiol. 42, 4679-4685

77 Schmid, M., Oehme, R., Schalasta, G., Brockmann, S., Kimmig, P. and Enders, G. (2004) Fast detection of Noroviruses using a real-time PCR assay and automated sample preparation. BMC Infect. Dis. 4, 15

78 Schwarz, B. A., Bange, R., Vahlenkamp, T. W., Johne, R. and Muller, H. (2002) Detection and quantitation of group A rotaviruses by competitive and real-time reverse transcription-polymerase chain reaction. J. Virol. Methods 105, 277-285

79 Pang, X. L., Lee, B., Boroumand, N., Leblanc, B., Preiksaitis, J. K. and Yu Ip, C. C. (2004) Increased detection of rotavirus using a real time reverse transcription-polymerase chain reaction (RT-PCR) assay in stool specimens from children with diarrhea. J. Med. Virol. 72, 496-501

80 Kang, G., Iturriza-Gomara, M., Wheeler, J. G. et al. (2004) Quantitation of group A rotavirus by real-time reverse-transcription-polymerase chain reaction: correlation with clinical severity in children in South India. J. Med. Virol. 73, 118-122

81 Mulder, J., McKinney, N., Christopherson, C., Sninsky, J., Greenfield, L. and Kwok, S. (1994) Rapid and simple PCR assay for quantitation of human immunodeficiency virus type 1 RNA in plasma: application to acute retroviral infection. J. Clin. Microbiol. 32, 292-300

82 Sun, R., Ku, J., Jayakar, H. et al. (1998) Ultrasensitive reverse transcription-PCR assay for quantitation of human immunodeficiency virus type 1 RNA in plasma. J. Clin. Microbiol. 36, 2964-2969

83 Havlir, D. V., Bassett, R., Levitan, D. et al. (2001) Prevalence and predictive value of intermittent viremia with combination hiv therapy. JAMA, J. Am. Med. Assoc. 286, 171-179

84 Palmer, S., Wiegand, A. P., Maldarelli, F. et al. (2003) New real-time reverse transcriptase-initiated PCR assay with single-copy sensitivity for human immunodeficiency virus type 1 RNA in plasma. J. Clin. Microbiol. 41, 4531-4536

85 Ruelle, J., Mukadi, B. K., Schutten, M. and Goubau, P. (2004) Quantitative real-time PCR on Lightcycler for the detection of human immunodeficiency virus type 2 (HIV-2). J. Virol. Methods 117, 67-74

86 Leutenegger, C. M., Higgins, J., Matthews, T. B. et al. (2001) Real-time TaqMan PCR as a specific and more sensitive alternative to the branched-chain DNA assay for quantitation of simian immunodeficiency virus RNA. AIDS Res. Hum. Retroviruses 17, 243-251

87 Gibellini, D., Vitone, F., Gori, E., La Placa, M. and Re, M. C. (2004) Quantitative detection of human immunodeficiency virus type 1 (HIV-1) viral load by SYBR green real-time RT-PCR technique in HIV-1 seropositive patients. J. Virol. Methods 115, 183-189

88 Klein, S. A., Karsten, S., Ruster, B. et al. (2003) Comparison of TaqMan real-time PCR and p24 Elisa for quantification of in vitro HIV-1 replication. J. Virol. Methods 107, 169-175

89 Candotti, D., Temple, J., Owusu-Ofori, S. and Allain, J. P. (2004) Multiplex real-time quantitative RT-PCR assay for hepatitis $B$ virus, hepatitis $C$ virus, and human immunodeficiency virus type 1. J. Virol. Methods 118, $39-47$

90 Sano, T., Smith, C. L. and Cantor, C. R. (1992) ImmunoPCR: very sensitive antigen detection by means of specific antibody-DNA conjugates. Science 258, 120-122
91 Sims, P. W., Vasser, M., Wong, W. L., Williams, P. M. and Meng, Y. G. (2000) Immunopolymerase chain reaction using real-time polymerase chain reaction for detection. Anal. Biochem. 281, 230-232

92 Henterich, N., Osman, A. A., Mendez, E. and Mothes, T. (2003) Assay of gliadin by real-time immunopolymerase chain reaction. Nahrung 47, 345-348

93 Barletta, J. M., Edelman, D. C. and Constantine, N. T. (2004) Lowering the detection limits of HIV-1 viral load using real-time immuno-PCR for HIV-1 p24 antigen. Am. J. Clin. Pathol. 122, 20-27

94 Hochhaus, A., Reiter, A., Skladny, H., Reichert, A., Saussele, S. and Hehlmann, R. (1998) Molecular monitoring of residual disease in chronic myelogenous leukemia patients after therapy. Recent Results Cancer Res. 144, 36-45

95 Jones, C. D., Yeung, C. and Zehnder, J. L. (2003) Comprehensive validation of a real-time quantitative bcr-abl assay for clinical laboratory use. Am. J. Clin. Pathol. 120, 42-48

96 Guo, J. Q., Lin, H., Kantarjian, H. et al. (2002) Comparison of competitive-nested PCR and real-time PCR in detecting BCR-ABL fusion transcripts in chronic myeloid leukemia patients. Leukemia 16, 2447-2453

97 Kim, Y. J., Kim, D. W., Lee, S. et al. (2002) Comprehensive comparison of FISH, RT-PCR, and RQ-PCR for monitoring the BCR-ABL gene after hematopoietic stem cell transplantation in CML. Eur. J. Haematol. 68, 272-280

98 Raanani, P., Ben-Bassat, I., Gan, S. et al. (2004) Assessment of the response to imatinib in chronic myeloid leukemia patients: comparison between the FISH, multiplex and RT-PCR methods. Eur. J. Haematol. $73,243-250$

99 Lion, T., Izraeli, S., Henn, T., Gaiger, A., Mor, W. and Gadner, H. (1992) Monitoring of residual disease in chronic myelogenous leukemia by quantitative polymerase chain reaction. Leukemia 6, 495-499

100 Elmaagacli, A. H., Beelen, D. W., Opalka, B., Seeber, S. and Schaefer, U. W. (2000) The amount of BCR-ABL fusion transcripts detected by the real-time quantitative polymerase chain reaction method in patients with Philadelphia chromosome positive chronic myeloid leukemia correlates with the disease stage. Ann. Hematol. 79, 424-431

101 Moravcova, J., Nadvornikova, S., Lukasova, M. and Klamova, H. (1999) Polymerase chain reaction analyses should be used as a basis for clinical decision making in patients with chronic myelogenous leukemia. Blood 94, 3609-3611

102 Goldman, J. M., Kaeda, J. S., Cross, N. C., Hochhaus, A. and Hehlmann, R. (1999) Clinical decision making in chronic myeloid leukemia based on polymerase chain reaction analysis of minimal residual disease. Blood $\mathbf{9 4}$ 1484-1486

103 Hardling, M., Wei, Y., Palmqvist, L. et al. (2004) Serial monitoring of BCR-ABL transcripts in chronic myelogenous leukemia (CML) treated with imatinib mesylate. Med. Oncol. 21, 349-358

104 Faderl, S., Talpaz, M., Kantarjian, H. M. and Estrov, Z. (1999) Should polymerase chain reaction analysis to detect minimal residual disease in patients with chronic myelogenous leukemia be used in clinical decision making? Blood 93, 2755-2759

105 Johnson, P. W., Swinbank, K., MacLennan, S. et al. (1999) Variability of polymerase chain reaction detection of the bcl-2-IgH translocation in an international multicentre study. Ann. Oncol. 10, 1349-1354

106 Gabert, J. (1999) Detection of recurrent translocations using real time PCR; assessment of the technique for diagnosis and detection of minimal residual disease. Haematologica 84 (Suppl. EHA-4), 107-109

107 Emig, M., Saussele, S., Wittor, H. et al. (1999) Accurate and rapid analysis of residual disease in patients with CML using specific fluorescent hybridization probes for real time quantitative RT-PCR. Leukemia 13, 1825-1832 
108 Eder, M., Battmer, K., Kafert, S., Stucki, A., Ganser, A. and Hertenstein, B. (1999) Monitoring of BCR-ABL expression using real-time RT-PCR in CML after bone marrow or peripheral blood stem cell transplantation. Leukemia 13, 1383-1389

109 Olavarria, E., Kanfer, E., Szydlo, R. et al. (2001) Early detection of BCR-ABL transcripts by quantitative reverse transcriptase-polymerase chain reaction predicts outcome after allogeneic stem cell transplantation for chronic myeloid leukemia. Blood 97, 1560-1565

110 Preudhomme, C., Revillion, F., Merlat, A. et al. (1999) Detection of BCR-ABL transcripts in chronic myeloid leukemia (CML) using a 'real time' quantitative RT-PCR assay. Leukemia 13, 957-964

111 Pui, C. H. and Evans, W. E. (1998) Acute lymphoblastic leukemia. N. Engl. J. Med. 339, 605-615

112 Gutierrez, M. I., Timson, G., Siraj, A. K. et al. (2005) Single Monochrome Real-Time RT-PCR Assay for Identification, Quantification, and Breakpoint Cluster Region Determination of $\mathrm{t}(9 ; 22)$ Transcripts. J. Mol. Diagn. 7, 40-47

113 Choppa, P. C., Gomez, J., Vall, H. G., Owens, M., Rappaport, H. and Lopategui, J. R. (2003) A novel method for the detection, quantitation, and breakpoint cluster region determination of $\mathrm{t}(15 ; 17)$ fusion transcripts using a one-step real-time multiplex RT-PCR. Am. J. Clin. Pathol. 119, 137-144

114 Bustin, S. A. and Dorudi, S. (1998) Molecular assessment of tumour stage and disease recurrence using PCR-based assays. Mol. Med. Today 4, 389-396

115 Mocellin, S., Rossi, C. R., Pilati, P., Nitti, D. and Marincola, F. M. (2003) Quantitative real-time PCR: a powerful ally in cancer research. Trends Mol. Med. 9, 189-195

116 Bustin, S. A., Siddiqi, S., Ahmed, S., Hands, R. and Dorudi, S. (2004) Quantification of cytokeratin 20, carcinoembryonic antigen and guanylyl cyclase C mRNA levels in lymph nodes may not predict treatment failure in colorectal cancer patients. Int. J. Cancer 108, 412-417

117 Schuster, R., Max, N., Mann, B. et al. (2004) Quantitative real-time RT-PCR for detection of disseminated tumor cells in peripheral blood of patients with colorectal cancer using different mRNA markers. Int. J. Cancer 108, 219-227

118 Keilholz, U., Willhauck, M., Rimoldi, D. et al. (1998) Reliability of reverse transcription-polymerase chain reaction (RT-PCR)-based assays for the detection of circulating tumour cells: a quality-assurance initiative of the EORTC Melanoma Cooperative Group. Eur. J. Cancer 34, 750-753

119 Bustin, S. A. and Dorudi, S. (2004) Gene expression profiling for molecular staging and prognosis prediction in colorectal cancer. Expert Rev. Mol. Diagn. 4, 599-607

120 Vlems, F. A., Ladanyi, A., Gertler, R. et al. (2003) Reliability of quantitative reverse-transcriptasePCR-based detection of tumour cells in the blood between different laboratories using a standardised protocol. Eur. J. Cancer 39, 388-396

121 Northover, J. M. (1997) Staging and management of colorectal cancer. World J. Surg. 21, 672-677

122 Gill, S., Thomas, R. R. and Goldberg, R. M. (2003) Review article: colorectal cancer chemotherapy. Aliment. Pharmacol. Ther. 18, 683-692

123 Tsavellas, G., Patel, H. and Allen-Mersh, T. G. (2001) Detection and clinical significance of occult tumour cells in colorectal cancer. Br. J. Surg. 88, 1307-1320

124 Miyake, Y., Fujiwara, Y., Ohue, M. et al. (2000) Quantification of micrometastases in lymph nodes of colorectal cancer using real-time fluorescence polymerase chain reaction. Int. J. Oncol. 16, 289-293

125 Oberg, A. N., Lindmark, G. E., Israelsson, A. C., Hammarstrom, S. G. and Hammarstrom, M. L. (2004) Detection of occult tumour cells in lymph nodes of colorectal cancer patients using real-time quantitative RT-PCR for CEA and CK20 mRNAS. Int. J. Cancer 111, $101-110$
126 Ho, S. B., Hyslop, A., Albrecht, R. et al. (2004) Quantification of colorectal cancer micrometastases in lymph nodes by nested and real-time reverse transcriptase-PCR analysis for carcinoembryonic antigen. Clin. Cancer Res. 10, 5777-5784

127 Bustin, S. A., Gyselman, V. G., Williams, N. S. and Dorudi, S. (1999) Detection of cytokeratins $19 / 20$ and guanylyl cyclase $\mathrm{C}$ in peripheral blood of colorectal cancer patients. Br. J. Cancer 79, 1813-1820

128 Bostick, P. J., Chatterjee, S., Chi, D. D. et al. (1998) Limitations of specific reverse-transcriptase polymerase chain reaction markers in the detection of metastases in the lymph nodes and blood of breast cancer patients. J. Clin. Oncol. 16, 2632-2640

129 Guo, J., Xiao, B., Zhang, X. et al. (2004) Combined use of positive and negative immunomagnetic isolation followed by real-time RT-PCR for detection of the circulating tumor cells in patients with colorectal cancers. J. Mol. Med. 82, 768-774

130 Ito, S., Nakanishi, H., Hirai, T. et al. (2002) Quantitative detection of CEA expressing free tumor cells in the peripheral blood of colorectal cancer patients during surgery with real-time RT-PCR on a LightCycler. Cancer Lett. 183, 195-203

131 Miura, M., Ichikawa, Y., Tanaka, K. et al. (2003) Real-time PCR (TaqMan PCR) quantification of carcinoembryonic antigen (CEA) mRNA in the peripheral blood of colorectal cancer patients. Anticancer Res. 23, 1271-1276

132 Wong, I. H., Yeo, W., Chan, A. T. and Johnson, P. J. (2001) Quantitative relationship of the circulating tumor burden assessed by reverse transcription-polymerase chain reaction for cytokeratin 19 mRNA in peripheral blood of colorectal cancer patients with Dukes' stage, serum carcinoembryonic antigen level and tumor progression. Cancer Lett. 162, 65-73

133 Guller, U., Zajac, P., Schnider, A. et al. (2002) Disseminated single tumor cells as detected by real-time quantitative polymerase chain reaction represent a prognostic factor in patients undergoing surgery for colorectal cancer. Ann. Surg. 236, 768-775

134 Compton, C., Fenoglio-Preiser, C. M., Pettigrew, N. and Fielding, L. P. (2000) American Joint Committee on Cancer Prognostic Factors Consensus Conference: Colorectal Working Group. Cancer 88, 1739-1757

135 Chambers, A. F., Groom, A. C. and MacDonald, I. C. (2002) Dissemination and growth of cancer cells in metastatic sites. Nat. Rev. Cancer 2, 563-572

136 Zetter, B. R. (1990) The cellular basis of site-specific tumor metastasis. New Engl. J. Med. 322, 605-612

137 Fidler, I. J. (1990) Critical factors in the biology of human cancer metastasis: twenty-eighth G.H.A. Clowes memorial award lecture. Cancer Res. 50, 6130-6138

138 Souter, R. G., Wells, C., Tarin, D. and Kettlewell, M. G. (1985) Surgical and pathologic complications associated with peritoneovenous shunts in management of malignant ascites. Cancer 55, 1973-1978

139 Fidler, I. J. (1990) Host and tumour factors in cancer metastasis. Eur. J. Clin. Invest. 20, 481-486

140 Lee, K. H., McKenna, M. J., Sewell, W. F. and Ung, F. (1997) Ribonucleases may limit recovery of ribonucleic acids from archival human temporal bones. Laryngoscope $107,1228-1234$

141 Mizuno, T., Nagamura, H., Iwamoto, K. S. et al. (1998) RNA from decades-old archival tissue blocks for retrospective studies. Diagn. Mol. Pathol. 7, 202-208

142 Coombs, N. J., Gough, A. C. and Primrose, J. N. (1999) Optimisation of DNA and RNA extraction from archival formalin-fixed tissue. Nucleic Acids Res. 27, e12

143 Lewis, F., Maughan, N. J., Smith, V., Hillan, K. and Quirke, P. (2001) Unlocking the archive-gene expression in paraffin-embedded tissue. J. Pathol. 195, 66-71

144 Bibikova, M., Talantov, D., Chudin, E. et al. (2004) Quantitative gene expression profiling in formalin-fixed, paraffin-embedded tissues using universal bead arrays. Am. J. Pathol. 165, 1799-1807

145 Bibikova, M., Yeakley, J. M., Chudin, E. et al. (2004) Gene expression profiles in formalin-fixed, paraffin-embedded tissues obtained with a novel assay for microarray analysis. Clin. Chem. 50, 2384-2386 
146 Zhang, J. and Byrne, C. D. (1999) Differential priming of RNA templates during cDNA synthesis markedly affects both accuracy and reproducibility of quantitative competitive reverse-transcriptase PCR. Biochem. J. 337, 231-241

147 Stahlberg, A., Hakansson, J., Xian, X., Semb, H. and Kubista, M. (2004) Properties of the reverse transcription reaction in mRNA quantification. Clin. Chem. 50, 509-515

148 Frech, B. and Peterhans, E. (1994) RT-PCR: 'background priming' during reverse transcription. Nucleic Acids Res. 22, 4342-4343

149 Lekanne Deprez, R. H., Fijnvandraat, A. C., Ruijter, J. M. and Moorman, A. F. (2002) Sensitivity and accuracy of quantitative real-time polymerase chain reaction using SYBR green I depends on cDNA synthesis conditions. Anal. Biochem. 307, 63-69

150 Cone, R. W., Hobson, A. C. and Huang, M. L. (1992) Coamplified positive control detects inhibition of polymerase chain reactions. J. Clin. Microbiol. 30, 3185-3189

151 Wilson, I. G. (1997) Inhibition and facilitation of nucleic acid amplification. Appl. Environ. Microbiol. 63, 3741-3751

152 Golenberg, E. M., Bickel, A. and Weihs, P. (1996) Effect of highly fragmented DNA on PCR. Nucleic Acids Res. 24, 5026-5033

153 Beutler, E., Gelbart, T. and Kuhl, W. (1990) Interference of heparin with the polymerase chain reaction. Biotechniques 9, 166

154 Akane, A., Matsubara, K., Nakamura, H., Takahashi, S. and Kimura, K. (1994) Identification of the heme compound copurified with deoxyribonucleic acid (DNA) from bloodstains, a major inhibitor of polymerase chain reaction (PCR) amplification. J. Forensic Sci. 39, 362-372

155 Chen, Z., Swisshelm, K. and Sager, R. (1994) A cautionary note on reaction tubes for differential display and cDNA amplification in thermal cycling. Biotechniques 16, 1002-1006
156 Burgos, J., Ramirez, C., Tenorio, R., Sastre, I. and Bullido, M. (2002) Influence of reagents formulation on real-time PCR parameters. Mol. Cell. Probes 16, 257

157 Al Soud, W. A. and Radstrom, P. (1998) Capacity of nine thermostable DNA polymerases To mediate DNA amplification in the presence of PCRinhibiting samples. Appl. Environ. Microbiol. 64, 3748-3753

158 Poddar, S. K., Sawyer, M. H. and Connor, J. D. (1998) Effect of inhibitors in clinical specimens on Taq and Tth DNA polymerase-based PCR amplification of influenza A virus. J. Med. Microbiol. 47, 1131-1135

159 Wiedbrauk, D. L., Werner, J. C. and Drevon, A. M. (1995) Inhibition of PCR by aqueous and vitreous fluids. J. Clin. Microbiol. 33, 2643-2646

160 Bolufer, P., Lo, C. F., Grimwade, D. et al. (2001) Variability in the levels of PML-RARa fusion transcripts detected by the laboratories participating in an external quality control program using several reverse transcription polymerase chain reaction protocols. Haematologica 86, 570-576

161 Mifflin, T. E., Estey, C. A. and Felder, R. A. (2000) Robotic automation performs a nested RT-PCR analysis for HCV without introducing sample contamination. Clin. Chim. Acta 290, 199-211

162 Walker, N. J. (2002) A technique whose time has come. Science 296, 557-559

163 Liu, J., Enzelberger, M. and Quake, S. (2002) A nanoliter rotary device for polymerase chain reaction. Electrophoresis 23, 1531-1536

164 Winter, H., Korn, K. and Rigler, R. (2004) Direct gene expression analysis. Curr. Pharm. Biotechnol. 5, 191-197

165 Braslavsky, I., Hebert, B., Kartalov, E. and Quake, S. R. (2003) Sequence information can be obtained from single DNA molecules. Proc. Natl. Acad. Sci. USA 100, 3960-3964 